\title{
Editorial
}

Respidion

\section{How Are You?}

\author{
Jean-William Fitting \\ Service de pneumologie, Centre Hospitalier Universitaire Vaudois, Lausanne, Switzerland
}

Patients with chronic obstructive pulmonary disease are plagued by the occurrence of acute exacerbations which unfavourably influence their quality of life and survival. Hospital admissions in this context also represent a major financial burden for the health care system [1]. Hence, an interest in identifying predictive factors of hospitalization is warranted with this disease [2].

A variety of potential predictive factors have been studied which can be grouped in three categories. The first and most straightforward category comprises the demographic and functional variables. Low $\mathrm{FEV}_{1}$, a known predictive factor of survival, was identified as an independent risk factor for hospitalizations in some studies [3-5], but not in others [6,7]. With regard to arterial blood gases, an elevated $\mathrm{PaCO}_{2}$ was found to be a predictive factor of hospital admissions in some $[6,7]$ but not in all studies [8]. Elevated pulmonary arterial pressure represents an independent risk factor, but it cannot be easily measured in every patient [7]. Similar conflicting conclusions were published for older age $[7,9]$, low body mass index $[7,8]$, and comorbid conditions $[4,8,10]$.

A second category of predictive factors can be defined as medical care-related variables. Repeated previous hospitalizations were found to predict further admissions in several studies $[3-6,10]$. Previous admissions may represent a global index of severity, but may also represent a 'confounder by indication' in the sense that it is perceived as signalling poor prognosis and induces itself further

\section{KARGER}

Fax +4161306 1234

E-Mail karger@karger.ch

www.karger.com
C) 2010 S. Karger AG, Basel

0025-7931/10/0801-0008\$26.00/0

Accessible online at:

www.karger.com/res admissions [4]. Being managed by a pulmonologist [4], the use of inhaled or oral corticosteroids $[8,10]$, the use of anticholinergics [4], and of long-term oxygen therapy $[5,7,10]$ were all found to be risk factors for hospitalizations. These observations merely indicate that hospital admissions occur in severe chronic obstructive pulmonary disease in spite of appropriate management. Thus, these variables are of little use to identify high-risk patients for specific interventions.

The third category relates to lifestyle and quality of life. A low quality of life or health status as assessed by standardized questionnaires was found to predict hospital admissions in a series of studies $[5,6,9,11,12]$. Among those patients with poor health status, anxiety was significantly associated with readmissions [5]. Lifestyle has to be considered as well: patients reporting a low or very low level of habitual physical activity are at high risk of hospital admission $[4,13]$. In the current issue of Respiration, Benzo et al. [14] confirm and extend these previous findings in a cohort of patients randomized to the medical arm of the National Emphysema Treatment Trial (NETT) [15]. Indeed, they established that low levels of self-reported physical activity and of health status, as well as the presence of self-reported anxiety, were predicting factors for hospital admissions in these patients with severe emphysema, whereas $\mathrm{FEV}_{1}$ and the BODE index were not. Thus, as shown by several previous authors, the patient's lifestyle, emotions and perception of health are 
better predictors of hospitalization than the traditional functional tests. Two points deserve particular attention in this study. Considering exercise-related variables, the predictor of hospitalizations was the self-reported habitual physical activity, but not the exercise capacity as assessed by the 6-min walk test. This appears as a message for respiratory rehabilitation, which should aim at enhancing not only exercise capacity but also exercise activ- ity that is actually accomplished in daily life. Considering methodology, the present study simplified it greatly by assessing physical activity, health status and anxiety in three questions, one for each item. This validated approach to predict the risk of hospitalization is easily accessible to the clinician. In fact, it can hardly be made simpler, except perhaps by a sincere 'How are you?' and by truly listening to the answer.

\section{References}

-1 Jansson SA, Andersson F, Borg S, Ericsson A, Jonsson E, Lundback B: Costs of COPD in Sweden according to disease severity. Chest 2002;122:1994-2002.

$\checkmark 2$ Bahadori K, FitzGerald JM: Risk factors of hospitalization and readmission of patients with COPD exacerbation - systematic review. Int J Chron Obstruct Pulmon Dis 2007; 2:241-251.

73 Garcia-Aymerich J, Monso E, Marrades RM, Escarrabill J, Felez MA, Sunyer J, et al: Risk factors for hospitalization for a chronic obstructive pulmonary disease exacerbation. EFRAM study. Am J Respir Crit Care Med 2001;164:1002-1007.

4 Garcia-Aymerich J, Farrero E, Felez MA, Izquierdo J, Marrades RM, Anto JM: Risk factors of readmission to hospital for a COPD exacerbation: a prospective study. Thorax 2003;58:100-105.

5 Gudmundsson G, Gislason T, Janson C, Lindberg E, Hallin R, Ulrik CS, et al: Risk factors for rehospitalisation in COPD: role of health status, anxiety and depression. Eur Respir J 2005;26:414-419.
6 Almagro P, Barreiro B, Ochoa de EA, Quintana S, Rodriguez CM, Heredia JL, et al: Risk factors for hospital readmission in patients with chronic obstructive pulmonary disease. Respiration 2006;73:311-317.

7 Kessler R, Faller M, Fourgaut G, Mennecier B, Weitzenblum E: Predictive factors of hospitalization for acute exacerbation in a series of 64 patients with chronic obstructive pulmonary disease. Am J Respir Crit Care Med 1999; 159:158-164.

8 Groenewegen KH, Schols AM, Wouters EF: Mortality and mortality-related factors after hospitalization for acute exacerbation of COPD. Chest 2003;124:459-467.

$>9$ Gadoury MA, Schwartzman K, Rouleau M, Maltais F, Julien M, Beaupre A, et al: Selfmanagement reduces both short- and longterm hospitalisation in COPD. Eur Respir J 2005;26:853-857.

10 Lau AC, Yam LY, Poon E: Hospital re-admission in patients with acute exacerbation of chronic obstructive pulmonary disease. Respir Med 2001;95:876-884.
1 Fan VS, Curtis JR, Tu SP, McDonell MB, Fihn SD: Using quality of life to predict hospitalization and mortality in patients with obstructive lung diseases. Chest 2002;122: 429-436.

12 Wang Q, Bourbeau J: Outcomes and healthrelated quality of life following hospitalization for an acute exacerbation of COPD. Respirology 2005; 10:334-340.

13 Garcia-Aymerich J, Lange P, Benet M, Schnohr P, Anto JM: Regular physical activity reduces hospital admission and mortality in chronic obstructive pulmonary disease: a population based cohort study. Thorax 2006; 61:772-778.

14 Benzo R, Chang C-CH, Farrell MH, Kaplan R, Ries A, Martinez FJ, et al: Physical activity, health status and risk of hospitalization in patients with severe chronic obstructive pulmonary disease. Respiration 2010;80:1018.

15 Fishman A, Martinez F, Naunheim K, Piantadosi S, Wise R, Ries A, et al: A randomized trial comparing lung-volume-reduction surgery with medical therapy for severe emphysema. N Engl J Med 2003;348:2059-2073. 